\author{
EVS27 \\ Barcelona, Spain, November 17-20, 2013
}

\title{
Fuel Efficiency Benefit for Electrified Vehicles from Advanced Spark-ignition Engine Technologies
}

\author{
B. Walton, A. Rousseau \\ Argonne National Laboratory, 9700 S. Cass Ave., Lemont, IL, USA, arousseau@anl.gov
}

\begin{abstract}
Worldwide fuel consumption regulations are becoming more and more stringent. As a result, car companies are looking at a wide portfolio of component technologies, including engines, transmissions, and electrification. This study examined fuel consumption reductions offered by a collection of advanced sparkignition (SI) engine technologies using full-vehicle simulations. High-fidelity engine models were developed to simulate Variable Valve Lift (VVL), Turbocharging and Downsizing (T), and Gasoline Direct Injection (DI) technologies in an incremental manner through an accumulative technology pathway. Measurements from these models were used to build full-vehicle simulations for each of the technologies across a spectrum of vehicle powertrain configurations with increased electrification. Each vehicle component was algorithmically sized to meet common performance criteria to ensure uniformity and comparability. The effects of vehicle hybridization and electrification on the technology fuel reductions while transitioning from conventional to mild, full, and plug-in hybrid configurations were investigated. Conventional vehicles were found to attain the highest overall benefits, while mild and full hybrid vehicles attained lower benefits. A negative correlation was found between engine technology benefit and vehicle hybridization. Over the pathway, cycles, and configurations investigated, average benefits for DI were found to be $8.0 \%$; VVL, 3.4\%; Turbocharging and downsizing, 9.7\%; and downsizing from 1.6 $\mathrm{L}$ to $1.2 \mathrm{~L}$, $2.7 \%$.
\end{abstract}

Keywords: Modelling, Simulation, Efficiency, ICE (Internal Combustion Engine), HEV (Hybrid Electric Vehicle)

\section{Introduction}

Since the creation of the gasoline-fueled automobile, the spark-ignition (SI) internal combustion engine has remained one of the most inefficient components of the vehicle powertrain, limited by the inherent nature of thermodynamics and the Otto Cycle. Thus, to achieve the highest overall vehicle efficiency, the internal combustion engine must be designed and controlled to approach the theoretical maximum efficiency offered by thermodynamics. To this end, much progress has been made in the past several decades creating advanced engine technologies that alter the thermodynamic cycle of combustion engines to reduce pumping losses, increase compression ratios etc.

It is highly useful to estimate the benefits offered by these technologies without building and calibrating expensive prototype engines. Previous studies have employed several analytical methods, 
such as Lumped Parameter Models and Partial Discrete Approximation, to estimate the fuel consumption benefits resulting from increasing the level of internal combustion engine technology ${ }^{[5]}$. The main drawback of such methods is their reliance on estimates of the synergies among technologies and their inability to account for the specific operating conditions experienced by the now wide spectrum of vehicle powertrain configurations.

In this study, full-vehicle simulations using data generated from high-fidelity engine models were employed to simulate energy consumption over a class of vehicle powertrain configurations with varying levels of hybridization. By employing high-fidelity engine modelling and full-vehicle simulation, both an accurate estimate of technology synergies and energy consumptions can be achieved while respecting the operating conditions of the given powertrains.

\section{Methodology}

The advanced engine technologies investigated in the study were Variable Valve Lift (VVL), Turbocharging and Downsizing (T), and Gasoline Direct Injection (DI). Each of these technologies was incrementally added to a GTPower engine model by IAV Automotive Engineering, Inc., and expert tuned to achieve comparable performance and size. Figure 1 shows the technology pathway used throughout the study. Each stage in the technology pathway represents an engine model with an added engine technology.

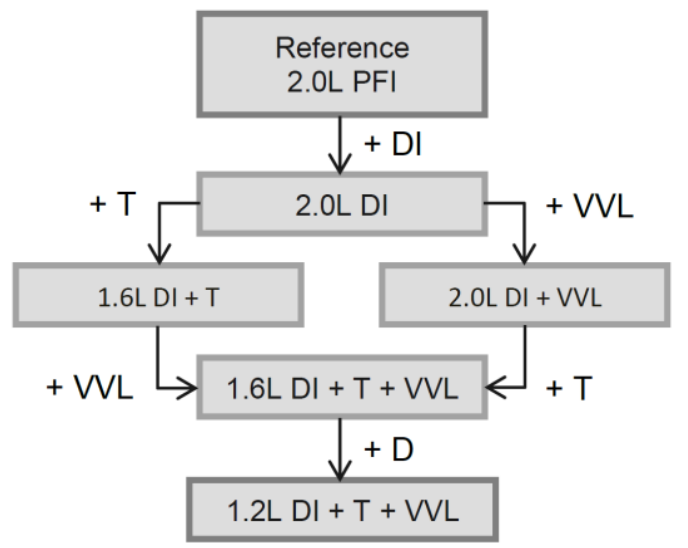

Figure 1: General Technology Pathway for the Incremental Addition of Engine Technologies

The technology pathway begins with a reference 2.0-L Port Fuel Injection (PFI) engine which is modified to add DI capabilities. From the 2.0-L
DI stage, a choice can be made whether to turbocharge and downsize (left path) or add VVL (right path). Both paths lead to a 1.6-L turbocharged, DI engine with VVI. This engine is further downsized to $1.2 \mathrm{~L}$ in the final stage.

Each of the 6 engine models in the technology pathway were integrated into 9 different vehicle configurations, making a total of 54 different powertrain-technology combinations. Table 1 outlines the powertrain configurations investigated. Three conventional, three mild hybrids, and three full hybrids were selected to represent the spectrum of available configurations.

Table 1: Investigated Vehicle Powertrain Configurations

\begin{tabular}{|l|l|c|}
\hline Configuration & Transmission & Drivetrain \\
\hline Conventional & $\begin{array}{l}\text { 6 Speed } \\
\text { Automatic }\end{array}$ & - \\
\hline Conventional & $\begin{array}{l}\text { 8 Speed } \\
\text { Automatic }\end{array}$ & - \\
\hline Conventional & $\begin{array}{l}\text { 8 Speed } \\
\text { Dual-Clutch }\end{array}$ & - \\
\hline Micro Hybrid & $\begin{array}{l}\text { 6 Speed } \\
\text { Automatic }\end{array}$ & Parallel \\
\hline $\begin{array}{l}\text { Mild Hybrid } \\
\text { BISG }\end{array}$ & $\begin{array}{l}\text { 6 Speed } \\
\text { Automatic }\end{array}$ & Parallel \\
\hline Mild Hybrid & 6 Speed \\
CISG & Automatic & Parallel \\
\hline $\begin{array}{l}\text { Pre-Transmission } \\
\text { HEV }\end{array}$ & $\begin{array}{l}\text { 6 Speed } \\
\text { Automatic }\end{array}$ & Parallel \\
\hline $\begin{array}{l}\text { Pre-Transmission } \\
\text { PHEV10 }\end{array}$ & $\begin{array}{l}\text { 6 Speed } \\
\text { Automatic }\end{array}$ & Parallel \\
\hline $\begin{array}{l}\text { Pre-Transmission } \\
\text { PHEV40 }\end{array}$ & $\begin{array}{l}\text { 6 Speed } \\
\text { Automatic }\end{array}$ & Parallel \\
\hline
\end{tabular}

Each vehicle uses the same component technologies, and, where applicable, the same hybrid architecture to maximize the comparability and achieve similar transient functionality throughout the drive cycles employed. Special care was taken to ensure that transmission shifting points occurred at similar points throughout the drive cycles for each of the different transmissions.

For each vehicle configuration, the engine power output was algorithmically scaled to meet a constant 0 to 60 miles per hour acceleration time of 9.0 seconds. For each of the powertraintechnology variants, UDDS (Urban Dynamometer Driving Schedule) and HWFET (Highway Federal Cycle) cycles were run to estimate fuel economy and energy consumption. The values reported 
represent the combined (55\% UDDS, 45\% HWFET) cycle weighted values.

Fuel consumption benefits were calculated by taking the percentage differences between fuel economy values at each technology stage for each vehicle. Comparisons were made across different vehicle configurations to analyse how different engine operating conditions impacted the benefits attained from each engine technology.

\section{Simulation Results}

Results from the simulated vehicles indicate that conventional and mild hybrid vehicles, where the engine is directly coupled to the road load and responsible for tractive torque, saw higher benefits compared to the full hybrids. Full hybrid configurations saw similar consumption reductions in most cases, but on average the resulting reductions are several percentages lower. Figure 2 shows the resulting fuel consumption reductions for each vehicle configuration, averages are taken across all powertrain configurations. The results for each technology are taken relative to the previous engine technology.

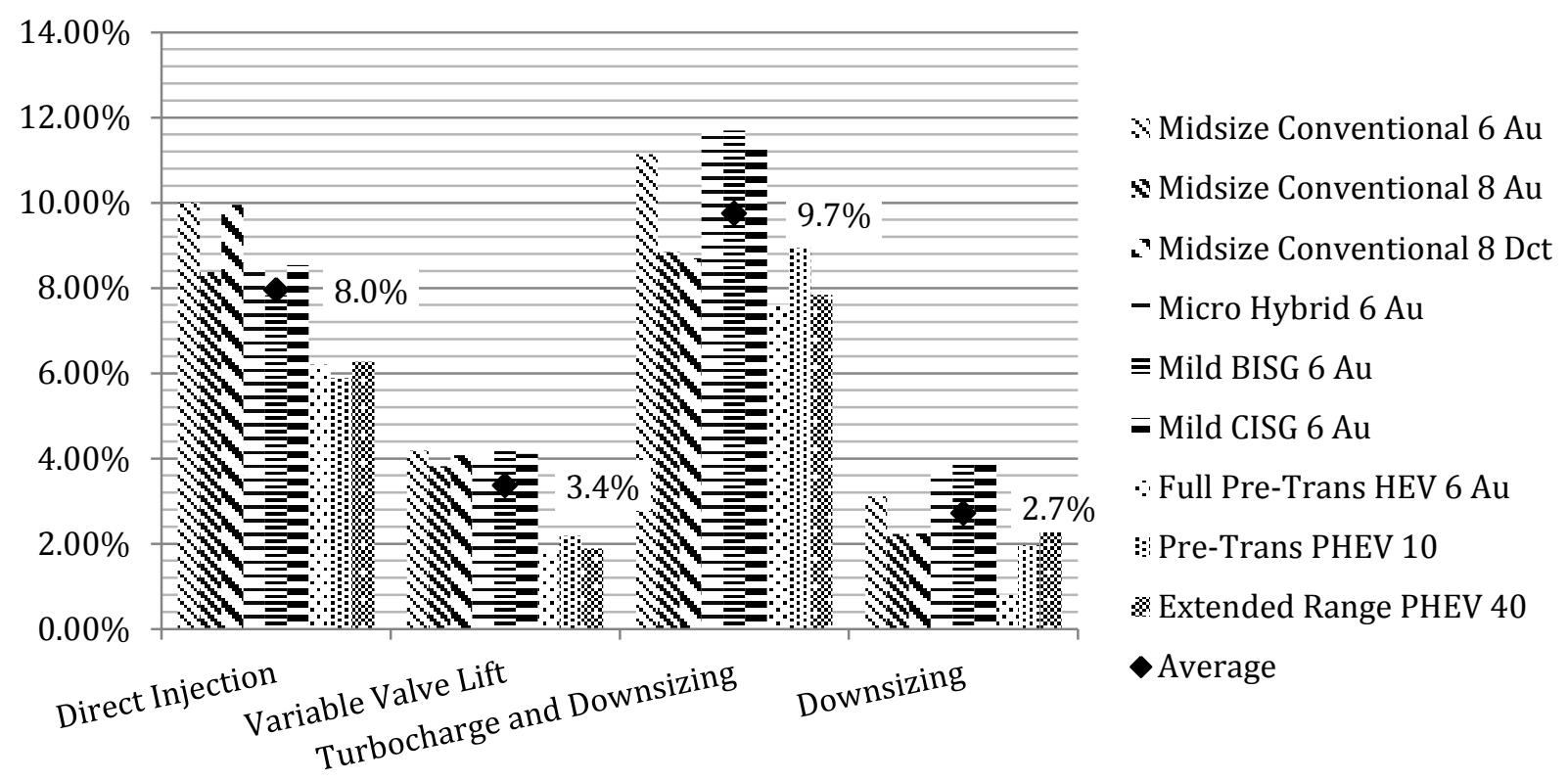

Figure 2: Fuel Consumption Reductions for Each Investigated Technology Relative to Previous Technology

Notable trends show a decrease in direct injection benefits as the level of hybridization increases. VVL appears to have constant fuel consumption reductions for the mild, conventional, and full hybrid cases; however, the full hybrid reductions are nearly half that of the mild and conventional cases. The mild hybrid cases achieve the highest benefits for $\mathrm{T}$, as well as pure downsizing in the $1.6-\mathrm{L}$ to $1.2-\mathrm{L}$ transition.
The full hybrid configurations demonstrate a lower benefit compared with the conventional and mild hybrid cases. This benefit can be justified by the full hybrid configuration's ability to operate its engines closer to the maximum engine efficiency for a larger portion of the drive cycle. Figure 3 shows the engine operating densities of both the full pre-transmission plug-in hybrid vehicle (PHEV)10 and conventional 6 speed automatic. The PHEV10 can be seen operating closer to the maximum efficiency point than the conventional. 

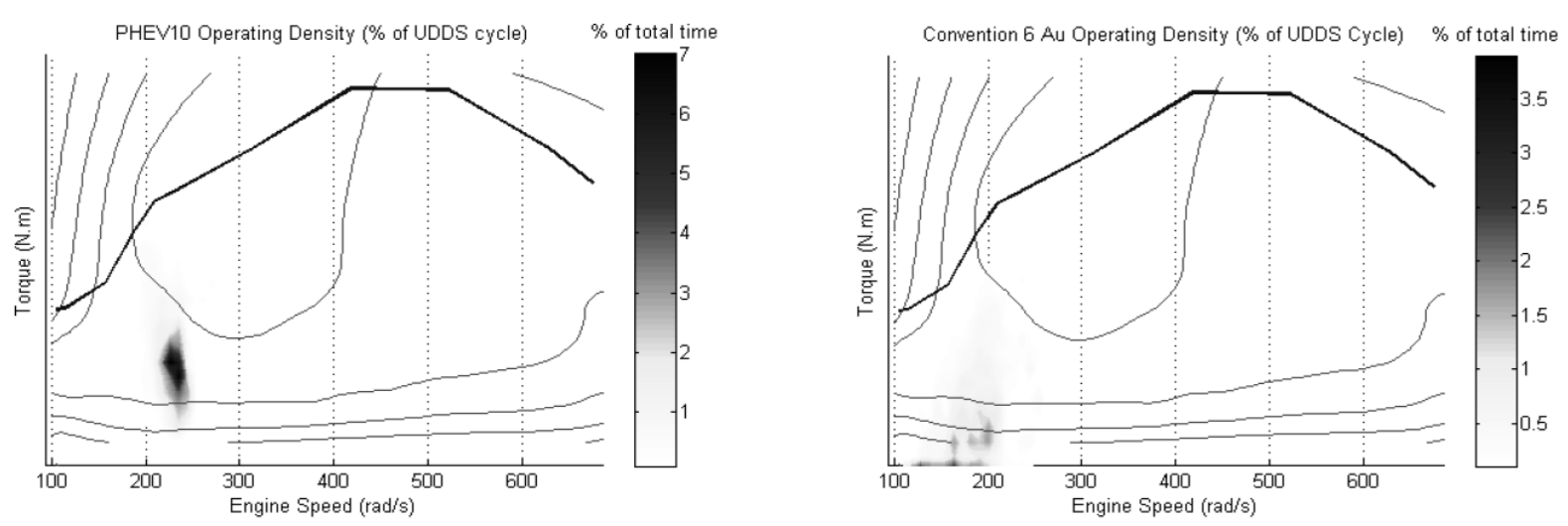

Figure 3: Engine Operating Regions for Full Hybrid and Conventional Cases

The full hybrids still see some benefit as a result of the maximum engine efficiency increasing across the technology pathway, but they do not operate in the regions of increased efficiency that the conventional road-load linked configurations do. There is less maximum engine efficiency increase overall than increase in the specific operating regions of the engine over the full technology pathway.

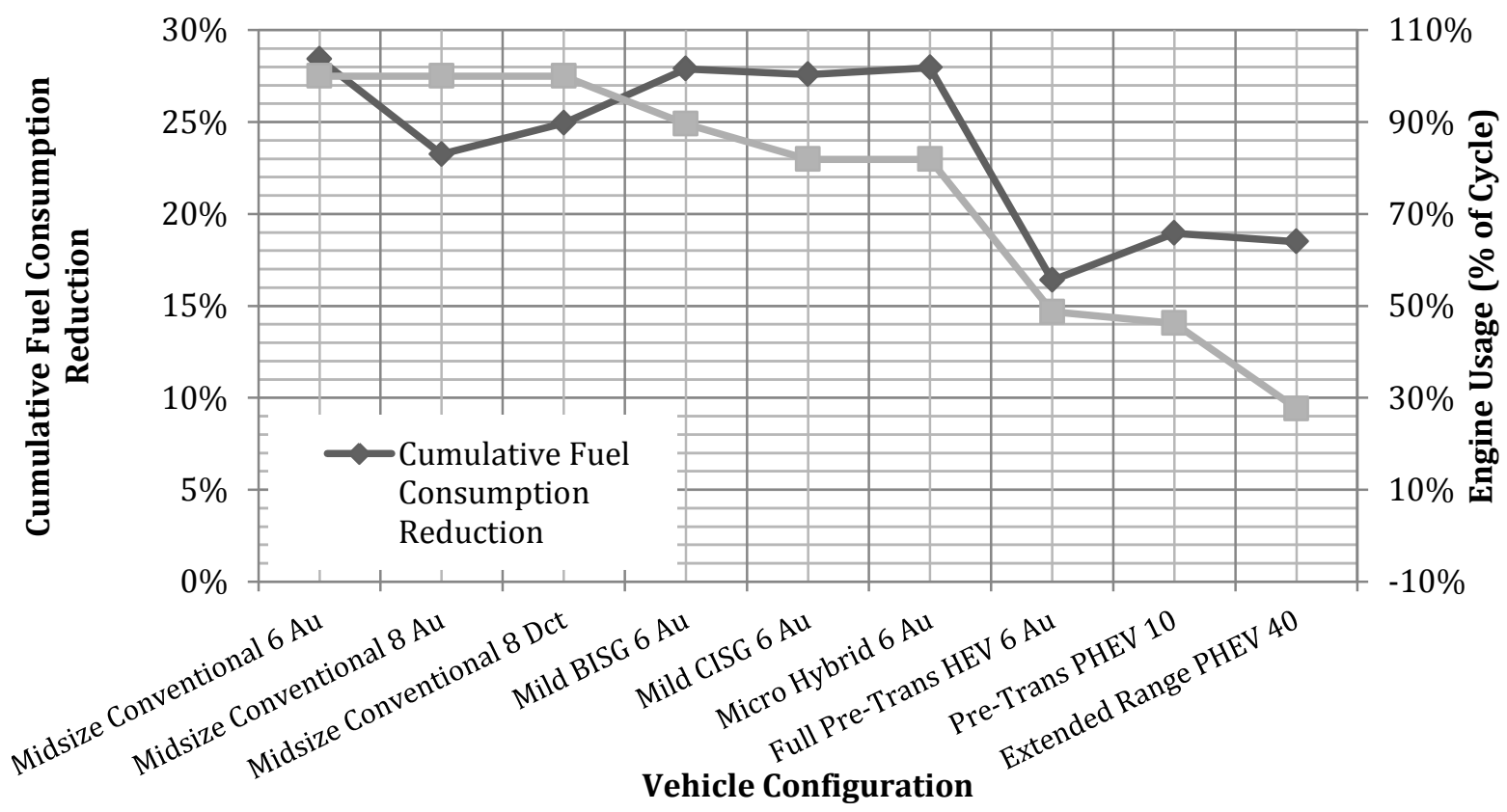

Figure 4: Cumulative Fuel Consumption Reductions Are Greater for Conventional and Mild Hybrid Vehicles

Figure 4 shows both the cumulative fuel consumption for each engine technology alongside the total engine usage for the cycle. The cumulative fuel consumption reduction represents the percentage of total reduction in fuel for each powertrain configuration between the most advanced 1.2-L DI, turbocharged engine with VVL and the baseline PFI engine. That is, keeping a fixed powertrain architecture and comparing the baseline engine fuel consumption with the most advanced engine's fuel consumption.

As shown in Figure 4, as the level of hybridization increases, engine usage decreases, as one would expect. However, the cumulative fuel consumption reductions remain near constant for the conventional, mild, and full hybrid vehicles. The hybrid vehicles see a large reduction in the benefits received from the increase in engine technology but still see some reductions. 
Table 2: Average Fuel Consumption Decreases for Engine Technologies

\begin{tabular}{|c|c|c|c|c|c|}
\hline \multirow[b]{2}{*}{ Technology } & \multicolumn{4}{|c|}{ Average Fuel Consumption Decrease (\%) } & \multirow{2}{*}{$\begin{array}{c}\text { Fuel Consumption } \\
\text { Reductions from Similar } \\
\text { Studies }(\%)\end{array}$} \\
\hline & All & Conventional & $\begin{array}{l}\text { Mild } \\
\text { Hybrid }\end{array}$ & $\begin{array}{c}\text { Full } \\
\text { Hybrid }\end{array}$ & \\
\hline Direct Injection & 8.0 & 9.4 & 8.3 & 6.1 & $10^{[3]}$ \\
\hline Variable Valve Lift & 3.4 & 4.0 & 4.1 & 2.0 & $4.8^{[2]}$ \\
\hline $\begin{array}{l}\text { Turbocharging and } \\
\text { Downsizing }\end{array}$ & 9.7 & 9.6 & 11.6 & 8.1 & $8-10^{[\mathrm{IT}}$ \\
\hline Downsizing & 2.7 & $2.5(12.1)$ & 3.8 & 1.8 & $(10)^{[4]}$ \\
\hline
\end{tabular}

Table 2 gives the average fuel consumption benefits seen among the engine technology stages. Again, mild hybrid cases obtain the most benefit across the technologies investigated. Full hybrids consistently place below the conventional, mild hybrid cases on average.

\subsection{Qualitative Comparison with Existing Studies}

Included in the final column of Table 2 are fuel consumption reductions for similar studies which specialized in a specific aspect of the investigated technology pathway. A direct quantitative comparison is not intended, however a qualitative comparison provides some level of confidence of the simulation results.

A study by Eichlseder, H. et al. [3] examined the direct injection benefits offered when upgrading from a PFI to a DI engine. The study reported a $10 \%$ reduction for several classes of conventional vehicles employing the combined UDDS and HWFET drive cycles. The study employed a similar technique to the one used herein, and the value attained closely resembles that of the simulation result for the conventional vehicle cases.

Sellnau, M. et al. [2] reported a $4.8 \%$ variable valve lift benefit using a real-world engine dynamometer test executing the EPA city cycle with cold start. They also reported a $5.1 \%$ benefit using their own modelling and simulation.

For turbocharging and downsizing, a paper by Petitjean, D. et al. [1] showed fuel consumption reductions could range from 8 to $10 \%$ depending on engine size reduction and desired peak power output. Their study employed real-world production vehicle data of peak power, engine displacement and fuel consumption to draw their estimates.
Finally, a study by Zaccardi, J. et al. [4] examined aggressively downsizing engines, specifically the transition from a $1.6 \mathrm{~L}$ PFI engine to several smaller variants. The comparison made was relative to the PFI, thus the comparison to this study should be made in relation to the sum of both the turbocharging and downsizing and pure downsizing benefits.

\subsection{Fuel Consumption Reductions from Direct Injection}

DI benefits appear directly correlated to the level of hybridization of the vehicle. Figure 5 shows a mild linear relationship between engine usage, an indicator of the hybridization of the vehicle, and the fuel consumption reduction for each of the investigated vehicle powertrain configurations.

As road load is removed from the engine and more freedom in choice of operating point is granted, the engine operates farther from the low torque and speed region. The low torque and speed region is where DI provides the most benefits over the PFI type engine through stratified charge. Thus the closer the engine operates to its peak efficiency point, the less fuel consumption reduction is seen for DI.

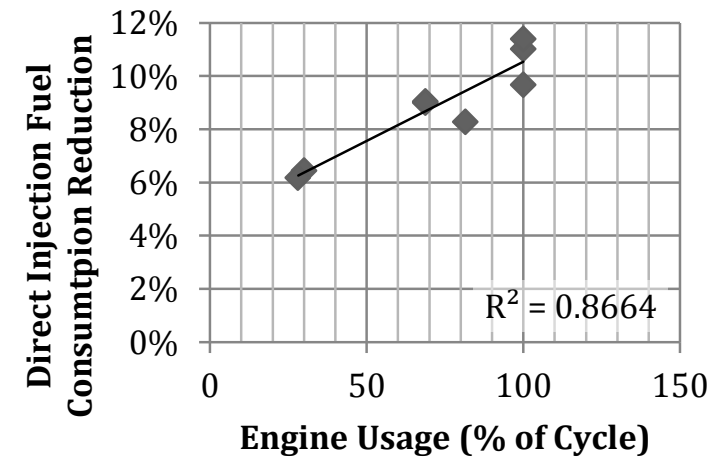

Figure 5: Fuel Consumption Reductions Increase as the Engine Is Used More throughout the Drive Cycle 
The ability to perform a stratified charge is one of the main benefits of DI over PFI. Stratified charge occurs during low load operation of the engine and was accounted for during vehicle simulations.

Since PFI draws fuel into the ignition cylinder during the intake stroke, the amount of fuel consumed must be proportional to the total volume of air drawn to create the correct air to fuel ratio. Stratified charge allows for a much lower fuel to air ratio by concentrating the fuel vapours around the ignition plug. The volume around the ignition plug has the correct air to fuel ratio, but the total air to fuel ratio for the cylinder is much greater.

Engines that are road coupled operate more frequently in the low torque and speed regions and thus see greater benefit. Hybrid operation of the engine still sees fuel consumption decreases; however, they are much less significant.

\subsection{Fuel Consumption Reductions from Variable Valve Lift}

The observed fuel consumption reductions for the introduction of VVL appeared to be near constant for the mild and conventional vehicles considered. Full hybrid vehicles saw some reductions (around 2\%) but were almost half of what the reduction was for the mild and conventional cases.

VVL was found to produce fuel consumption reductions of equal magnitude in both the operating regions of the conventional and mild hybrid cases. This led to the near constant benefits seen across both categories. The hybrid cases operated somewhat outside the area of greatest benefit, and thus saw only slight increases.

\subsection{Fuel Consumption Reductions from Turbocharging and Downsizing}

Turbocharging and downsizing produced the most significant fuel consumption reductions of all technologies considered. Transitioning from a DI engine with VVL to a turbocharged and downsized version resulted in a fuel consumption reduction on average of $9.7 \%$.
The combination of turbocharging and VVL created a large reduction in fuel consumption across the operating regions of all 3 powertrain configurations. Typically, turbocharging creates a fuel consumption increase across all speeds in the low-torque region of engine operation. This is usually taken as a trade-off to the increased overall power output of the engine.

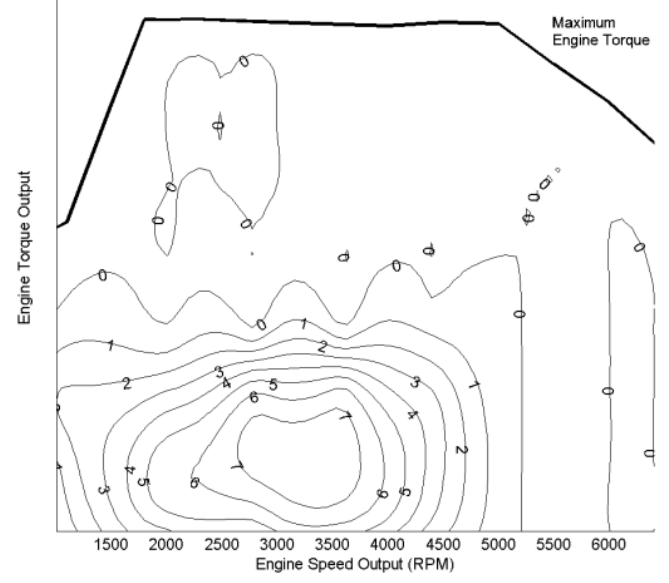

Figure 6: Efficiency Map Difference between Turbocharged and Turbocharged VVL Engines

By combining VVL with turbocharging and downsizing as was done in the third engine technology stage, the low-torque fuel consumption increase was almost negated. This allowed for the downsized engine to produce much higher power while maintaining an overall fuel consumption decrease over the DI with VVL engine.

Figure 6 shows the absolute differences in the efficiency mappings between the turbocharged and turbocharged VVL engines. Visible in the mapping are the large percentage increases caused by the addition of VVL to the turbocharged engine.

\subsection{Fuel Consumption Reductions from Aggressive Downsizing}

The final engine technology investigated was further downsizing of the already turbocharged 1.6-L engine. A fuel consumption reduction was found for all of the vehicle configurations, with the conventional and mild hybrid cases receiving more fuel consumption reduction than the average of the full hybrids.

For the full hybrid cases, increasing benefits are seen between the pre-transmission HEV and the pre-transmission PHEV. The HEV battery acts a buffer and must be constantly charge sustained, 
resulting in less control over when and how much the engine runs. This affects the benefits received from downsizing, since the engine operates in a different region than the PHEVs, which both see fuel consumption reductions comparable to the conventional vehicles.

\subsection{Additional Results}

Out of all the investigated vehicle configurations, the pre-transmission HEV was found to benefit least from the investigated engine technologies over the drive cycles considered.

Of considerable interest are the equivalent fuel economies found between different vehicle configurations with different technologies. For example, a conventional with 8 speed transmission, DI, and VVL had near identical fuel economy to that of a Belt Integrated Starter
Alternator (BISG) with 6 speed transmission and DI.

Figure 7 shows the average fuel consumptions for each vehicle powertrain configuration. The error bars represent the highest fuel consumptions of the PFI engine, and lowest fuel consumption provided by the 1.2-L T, DI, VVL engine.

The hybrid vehicles exhibit a much smaller range of improvement compared to the mild and conventional counterparts. Because of decreased reliance on the engine to provide power over the drive cycles, the fuel economy for each hybrid case appears to be dictated more by the size of the battery pack and the efficiencies of the electrical system than by the increased efficiency of the engine.

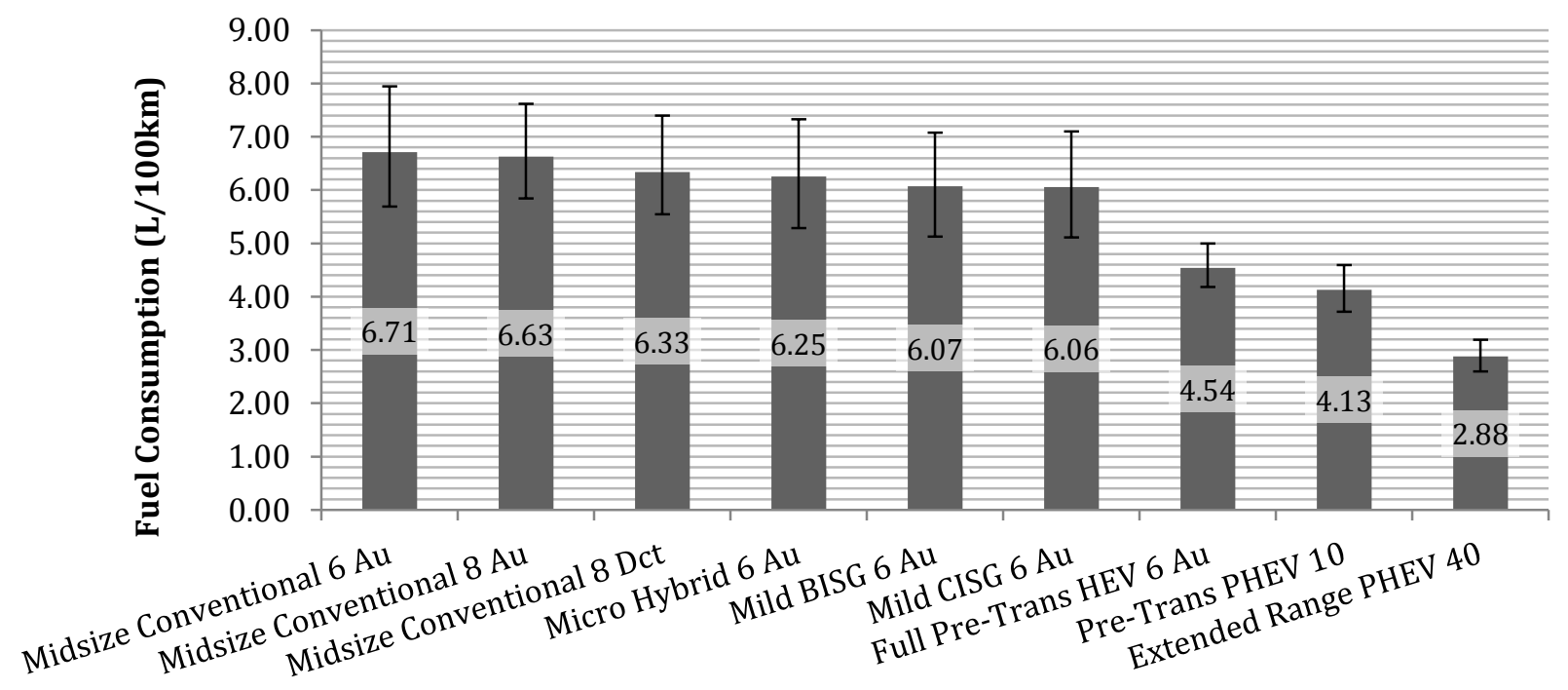

Figure 7: Average Fuel Consumptions for Powertrain Configurations

(Error bars indicate fuel consumptions between lowest and highest technology.)

Figure 8 shows the total fuel consumption decreases across each of the vehicle powertrain configurations for each engine technology. The fuel consumption decreases for conventional and mild hybrids is greater than that of the full hybrid configurations. The figure also shows the variance among the powertrain configurations when the engine technology is increased to the final technology stage. 

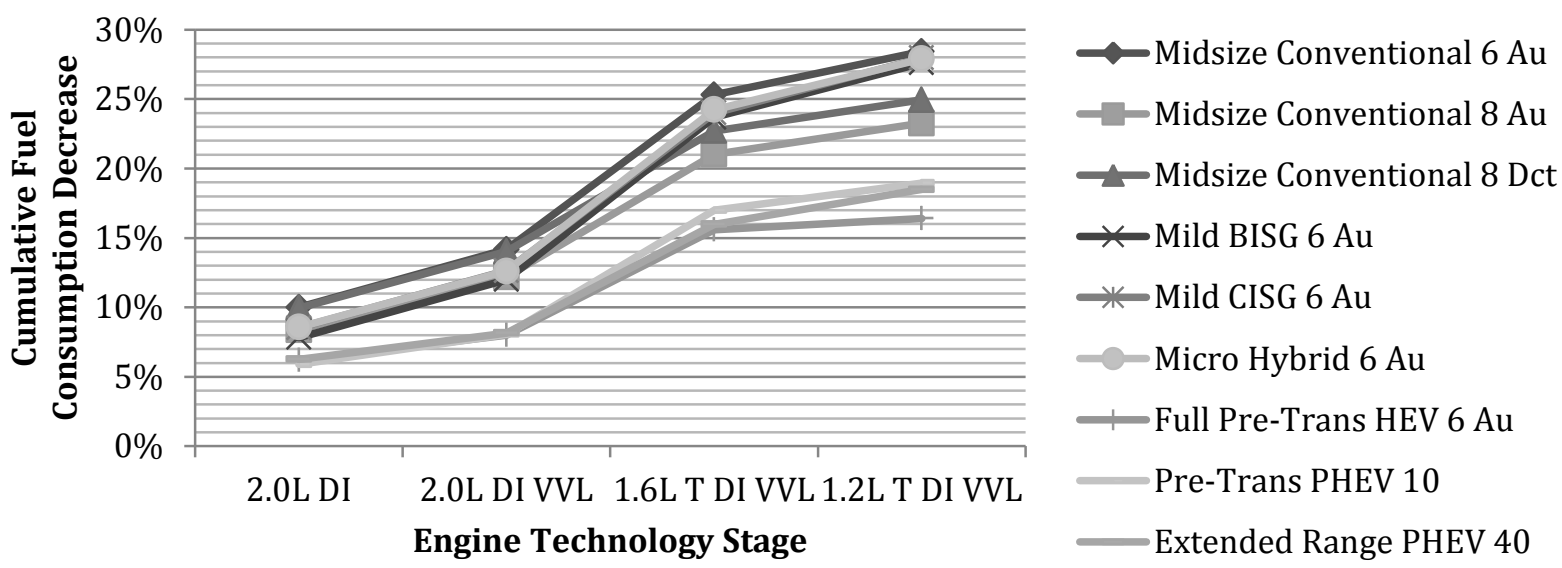

Figure 8: Cumulative Benefit across Technology Stages

Each of the powertrain configurations has a relatively consistent fuel consumption decrease, transitioning from the baseline PFI engine to the DI variant. However, as the technology level is increased, the total fuel consumption decrease seen by each powertrain configuration varies.

\section{Conclusions}

The use of the advanced engine technologies investigated can lead to significant decreases in fuel consumption (up to $27 \%$ over the drive cycles and engine technology pathway considered). The highest benefits were seen by conventional and mild hybrid vehicles whose operations were linked directly to traction torque. Average fuel consumption reductions for DI were $8.0 \%$; VVL, 3.4\%; turbocharging and downsizing, 9.7\%; and aggressive downsizing from $1.6 \mathrm{~L}$ to $1.2 \mathrm{~L}, 2.7 \%$.

Overall, the operating conditions of each vehicle configuration had a significant impact on the benefits resulting from each engine technology. Advanced engine technologies also provided significant benefits for hybrid vehicles, which could allow car manufacturers to meet the stringent fuel consumption regulations and consequently increase the vehicles' market penetration.

As a result, a complete system approach is necessary to properly select the appropriate combination of powertrain configuration and component technologies to minimize fuel consumption while maintaining acceptable performance and cost.

\section{Acknowledgments}

This work was supported by the U.S. Department of Energy's (DOE's) Office of Vehicle Technologies. The support of David Anderson is gratefully acknowledged. The submitted manuscript has been created by the UChicago Argonne, LLC, Operator of Argonne National Laboratory ("Argonne"). Argonne, a U.S. Department of Energy Office of Science laboratory, is operated under Contract No. DE-AC02-06CH11357. The U.S. Government retains for itself, and others acting on its behalf, a paid-up nonexclusive, irrevocable worldwide license in said article to reproduce, prepare derivative works, distribute copies to the public, and perform publicly and display publicly, by or on behalf of the Government.

\section{References}

[1] Petitjean, D., Bernardini, L., Middlemass, C., and Shahed, S., "Advanced Gasoline Engine Turbocharging Technology for Fuel Economy Improvements," SAE Technical Paper 2004-010988, 2004, doi:10.4271/2004-01-0988.

[2] Sellnau, M., Kunz, T., Sinnamon, J., and Burkhard, J., "2-step Variable Valve Actuation: System Optimization and Integration on an SI Engine," SAE Technical Paper 2006-01-0040, 2006, doi:10.4271/2006-01-0040.

[3] Eichlseder, H., Baumann, E., Müller, P., and Rubbert, S., "Gasoline Direct Injection - A Promising Engine Concept for Future Demands," SAE Technical Paper 2000-01-0248, 2000, doi:10.4271/2000-01-0248.

[4] Zaccardi, J., Pagot, A., Vangraefschepe, F., Dognin, C. et al., "Optimal Design for a Highly Downsized Gasoline Engine," SAE Technical 
Paper 2009-01-1794, 2009, doi:10.4271/2009-011794.

[5] Committee on the Assessment of Technologies for Improving Light-Duty Vehicle Fuel Economy; National Research Council. National Academy of Sciences, (2011). Assessment of fuel economy technologies for light-duty vehicles (ISBN: 9780309156073). Retrieved from National Academies Press website: http://www.nap.edu/openbook. php?record_id=12924.

\section{Authors}

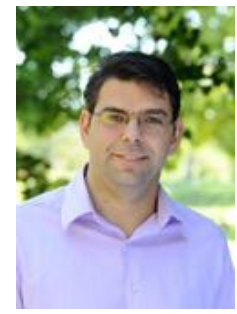

Aymeric Rousseau is the Manager of the Vehicle Modeling and Simulation Section at Argonne National Laboratory. He received his engineering diploma at the Industrial System Engineering School in La Rochelle, France in 1997. After working for PSA Peugeot Citroen in the Hybrid Electric Vehicle research department, he joined Argonne National Laboratory in 1999, where he is now responsible for the development of Autonomie and its applications.

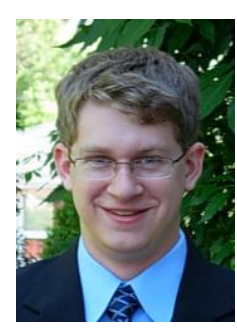

Brandon Walton is a junior student at the University of Waterloo in Waterloo, Canada. $\mathrm{He}$ is currently pursuing a bachelor's degree in science specializing in applied physics. His areas of interest include hybrid electric vehicles, control strategy development and the modelling/simulation of physical phenomena. $\mathrm{He}$ is currently the controls and modelling lead for the University of Waterloo advanced vehicle technology competition team. 